\title{
Analysis of the Band-Pass and Notch Filter with Dynamic Damping of Fractional Order Including Discrete Models
}

\author{
Marko Bošković, Tomislav B. Šekara, Milan R. Rapaić, \\ Budimir Lutovac, Miloš Daković, and Vidan Govedarica
}

\begin{abstract}
The paper presents analysis of the second order band-pass and notch filter with a dynamic damping factor $\beta_{\mathrm{d}}$ of fractional order. Factor $\beta_{\mathrm{d}}$ is given in the form of fractional differentiator of order $\alpha$, i.e. $\beta_{d}=\beta / s^{\alpha}$, where $\beta$ and $\alpha$ are adjustable parameters. The aim of the paper is to exploit an extra degree of freedom of presented filters to achieve the desired filter specifications and obtain a desired response in the frequency and time domain. Shaping of the frequency response enables achieving a better phase response compared to the integer-order counterparts which is of great concern in many applications. For the implementation purpose, the paper presents a comparison of four discretization techniques: the Osutaloup's Recursive Algorithm (ORA+Tustin), Continued Fractional Expansion (CFE+Tustin), Interpolation of Frequency Characteristic (IFC+Tustin) and recently proposed AutoRegressive with eXogenous input (ARX)-based direct discretization method.

Keywords - Butterworth filter, Discretization, Fractionalorder filter, Fractional calculus, Frequency response.
\end{abstract}

\section{INTRODUCTION}

$\mathrm{A}^{\mathrm{h}}$ large number of technical and natural phenomena exhibit a fractional-order (FO) dynamics which by itself leads to a widespread application of fractional calculus (FC) in numerous interdisciplinary fields of science and engineering. FC offers a large exploiting potential since it provides more accurate models than

Paper received April 12, 2018; revised June 26, 2018; accepted July 2, 2018. Date of publication July 31, 2018. The associate editor coordinating the review of this manuscript and approving it for publication was Prof. Branimir Reljin.

This paper is a revised and expanded version of the paper presented at the 25th Telecommunications Forum TELFOR 2017 [53].

This work is partially supported by Ministry of Education, Science and Technological Development of the Republic of Serbia under the Project TR-33020 (T.B.Š) and TR-32018, TR-33013 (M.R.R).

Marko Bošković and Milan R. Rapaić are with the Faculty of Technical Sciences, University of Novi Sad, Trg Dositeja Obradovića 6, 21000 Novi Sad, Serbia (e-mail: marko.boskovic@uns.ac.rs, rapaja@uns.ac.rs).

Tomislav B. Šekara is with the School of Electrical Engineering, University of Belgrade, Bulevar kralja Aleksandra 73, 11120 Belgrade, Serbia (e-mail: tomi@etf.rs).

Budimir Lutovac and Miloš Daković are with Faculty of Electrical Engineering, University of Montenegro, Džordža Vašingtona bb, 81000 Podgorica, Montenegro (e-mail: budo@ac.me, milos@ac.me).

Vidan Govedarica is with the Faculty of Electrical Engineering, University of East Sarajevo, Vuka Karadžića 30, 71123 East Sarajevo, Bosnia and Herzegovina (e-mail: vidangov@yahoo.com). classical integer-order ones [1]-[2]. Moreover, the use of fractional differ-integrators (derivatives and integrators) enables the characterization of FO systems with their entire history and modeling non-local and distributed effects. The history and fundamental theoretical aspects of FC may be found in [1]-[5].

The area of application of FC is increasing greatly and rapidly. FC is extensively used in: bioengineering and biomedical applications [6,7], analysis and synthesis of FO electrical elements [8]-[11], memristive FO systems [12], [13], power electronics for FO modeling power converters [14]-[16], digital image and signal processing [17], [18], electromagnetic theory [19], [20], timefractional telegrapher equations for modeling transmission lines [21], [22], control systems for designing $\mathrm{FO}$ controllers [23]-[27], mechanics [28], [29], diffusion and wave propagation [30]-[33], nanotechnology, agriculture, economy, etc.

There is a permanent progress in the application of FC to signal analysis and processing in the last twenty years. The main application advantage of FO filter is an extra degree of freedom allowing a more precise control of the attenuation slope, which is an efficient feature in biomedical engineering [34], [35]. Shaping the exact frequency response including a prespecified bandwidth is of great concern for many filter applications such as: PLLs (Phase Locked Loops), e.g. in [36] it is of great importance to remove a large negative phase angle in feedback loop in relay-based critical point estimation, as well as in the processing of biomedical signals (ECG, EEG etc.) [37].

The area of application of band-pass and band-stop filters is large: band-pass filters are widely used in wireless transceivers, optical microscopy, seismology, while band-stop filters are extensively used in the Riemann laser spectroscopy, RF applications, etc. That is why this paper is focused on the analysis of the second order band-pass and notch filter with FO dynamic damping factor $\beta_{\mathrm{d}}$. The factor $\beta_{\mathrm{d}}$ has a form of fractional differentiator of order $\alpha$, i.e. $\beta_{\mathrm{d}}=\beta / s^{\alpha}$, where fractional order $\alpha$ and adjustable real parameter $\beta$ are determined to meet specified requirements. For $\alpha=0$ and $\beta=\sqrt{2}$ filter is reduced to a classical second-order filter of Butterworth type. Actually, these parameters are adjusted to obtain a desired frequency and time domain response. 
This paper is organized as follows. First, a short introduction to the fractional calculus is given in Section 2. Section 3 elaborates the second order band-pass and notch filter with a fractional damping factor. Section 4 provides a comparison of four discretization methods for the purpose of effective digital implementation of considered filters. Section 5 gives concluding remarks of the paper.

\section{FUNDAMENTALS OF FRACTIONAL CALCULUS}

FO differ-integrator is an operator of FC which arises from a generalization of classical differentiation and integration operators. The transfer function of FO differintegrator is $s^{\alpha}$ where $s$ is the Laplace variable and $\alpha$ is an arbitrary real number. For a positive $\alpha$, differ-integrator is a generalization of classical integer order derivative, while for a negative $\alpha$ it is a generalization of repeated, or $n$ fold, integral.

Among many others, three most frequently used definitions for the FO derivative and integral operators are the Riemann-Liouville, Caputo and Grunwald-Letnikov definitions [3-5]. The left Riemann-Liouville (RL) fractional integral operator of order $\alpha$ is defined as

$$
{ }_{a} I_{t}^{\alpha} f(t)=\frac{1}{\Gamma(-\alpha)} \int_{a}^{t} \frac{f(\tau)}{(t-\tau)^{\alpha+1}} d \tau, \alpha \in \mathbb{R}, \alpha<0,
$$

where $a$ is a terminal point on interval and $\Gamma(z)=\int_{0}^{\infty} e^{-t} t^{z-1} d t, z \in \mathbb{C}$ is Euler's Gamma function. RL fractional derivative operator of order $\alpha$ is defined by

$$
{ }_{a} D_{t}^{\alpha} f(t)=\frac{1}{\Gamma(n-\alpha)} \frac{d^{n}}{d t^{n}} \int_{a}^{t} \frac{f(\tau)}{(t-\tau)^{\alpha+1-n}} d \tau,
$$

where $n-1<\alpha<n$. In applications the case $\alpha \in(0,1)$ is of the greatest importance when equation (2) is reduced to ${ }_{0} D_{t}^{\alpha} f(t)$ for $a=0$.

After adopting the definition, an intermediate step for frequency domain signal analysis is the calculation of the Laplace transform of RL derivative ${ }_{0} D_{t}^{\alpha} f(t)$. It simplifies calculations through the algebraic analysis of linear systems in complex $s$-domain. Assuming the existence of initial conditions in (2), the Laplace transform of ${ }_{0} D_{t}^{\alpha} f(t)$ is

$$
L\left\{{ }_{0} D_{t}^{\alpha} f(t)\right\}=s^{\alpha} F(s)-\left.\sum_{k=0}^{n-1} s^{k}\left({ }_{0} D_{t}^{\alpha-k-1} f\right)\right|_{t \rightarrow 0},
$$

while for zero initial conditions (3) is reduced to

$$
L\left\{{ }_{0} D_{t}^{\alpha} f(t)\right\}=s^{\alpha} F(s) .
$$

\section{ANALYSIS OF BAND-PASS AND NOTCH FILTER WITH FRACTIONAL-ORDER DAMPING FACTOR}

Nowadays, FO filters are a growing area of scientific research, so recently different studies of FO filters have been conducted. Papers [38, 39] introduce the FO Butterworth filter dealing with its analysis, active and passive synthesis while the design and implementation of FO Butterworth filter for processing biomedical EEG signals is considered in [37]. The FO Butterworth lowpass digital filter is designed in [40] for sharpening a digital image whose quality is adjusted through changing the FO of the filter. However, faster roll-off may be achieved, e.g. with the Chebyshev filter at the expense of ripples in pass and stop bands [41], so in [42] is developed a complex FO low-pass filter.

The most common types of analog filter types are the Butterworth, Chebyshev (I and II), Bessel and Elliptic. Let us set aside the Butterworth filter which is characterized by a maximally flat response with no ripple compared to the others. The magnitude frequency response rolls-off smoothly and monotonically, with a low-pass or highpass roll off of $20 \mathrm{~dB} / \mathrm{dec}$ for every pole. Thus, a third order Butterworth band-pass filter would have an attenuation rate of $-60 \mathrm{~dB} / \mathrm{dec}$ and $60 \mathrm{~dB} / \mathrm{dec}$. A classical integer-order analog Butterworth filter of order $n$ has a frequency magnitude response [43]

$$
|F(\mathrm{j} \omega)|=\frac{1}{\sqrt{1+\left(\frac{\omega}{\omega_{c}}\right)^{2 n}}}
$$

where $\omega_{\mathrm{c}}$ is the $3 \mathrm{~dB}$ cut-off frequency. For $n=2$ a corresponding transfer function for magnitude response (5) is

$$
F(s)=\frac{\omega_{c}^{2}}{s^{2}+\sqrt{2} \omega_{c} s+\omega_{c}^{2}},
$$

The most common filter structures are those based on the analog second-order filter. Hence, in this paper the second order band-pass filter is defined with a normalized transfer function

$$
F_{\text {bp }}(s)=\frac{\beta_{\mathrm{d}} s}{s^{2}+\beta_{\mathrm{d}} s+1}
$$

where $\beta_{\mathrm{d}}=\frac{\beta}{s^{\alpha}}$ is a dynamic FO damping parameter, $\alpha$ is a FO parameter, and $\beta$ is a real adjustable parameter. The parameter $\beta$ is generally independent of $\alpha$ and is used to meet specified requirements. The normalized cut-off frequency $\omega_{\mathrm{c}}=1 \mathrm{~s}^{-1}$ corresponds to Eq. (7), while by substituting $s$ with $s / \omega_{\mathrm{c}}$ in (7), the filter can be designed for a desired cut-off frequency $\omega_{\mathrm{c}}$.

On the basis of (7), the corresponding notch filter transfer function is defined as $F_{\mathrm{n}}(\mathrm{s})=1-F_{\mathrm{bp}}(\mathrm{s})$, i.e.

$$
F_{\mathrm{n}}(s)=\frac{s^{2}+1}{s^{2}+\beta_{\mathrm{d}} s+1}
$$

It is obvious that for $\alpha=0$ and $\beta=\sqrt{2}$ Eq. (7) and (8) are reduced to a classical integer-order band-pass and notch filter of Butterworth type, respectively, with the same characteristic equation of low-pass Butterworth filter in Eq. (6).

In order to improve a phase response and not deteriorate a magnitude response, parameter $\beta$ is determined following the idea in [44] to keep the same dominant dynamics which is determined with roots of denominator in Eq. (7) and (8). First, the overshoot $A_{\mathrm{p}}=4.32 \%$ in the unit-step response of the classical second-order low-pass 
Butterworth filter $F_{\mathrm{lp}}(s)=1 /\left(s^{2}+\sqrt{2} s+1\right)$ is calculated. Then, the unit-step response of FO low-pass counterpart of filters (7) and (8)

$$
F_{\text {lp }}(s)=\frac{1}{s^{2}+\beta_{\mathrm{d}} s+1}
$$

is determined via numerical inversion of Laplace transform which enables to calculate $\beta$ to keep the same $A_{\mathrm{p}}$ for different values of fractional order $\alpha$. The obtained unit-step response of filter (9) for $\alpha \in\{0 ; 0.1 ; 0.2 ; 0.3 ; 0.4 ; 0.5\}$. is shown in Fig. 1 , and the calculated values of $\beta$ are given in Table 1 .

The applied idea actually leads to preserving the same bandwidth of the systems since the dynamics of low-pass, band-pass and notch filters in Eq. (7)-(9) is determined by roots of the same characteristic equation $s^{2}+\beta s^{\alpha}+1$, which are shown in complex $s$-plane in Fig. 2 for $\alpha \in\{0 ; 0.1 ; 0.2 ; 0.3 ; 0.4 ; 0.5\}$.

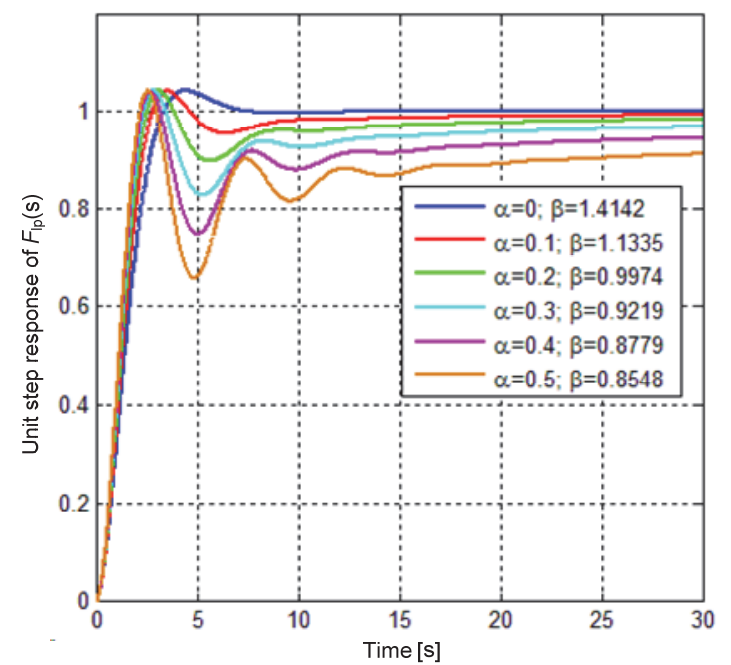

Fig. 1. Unit-step response of low-pass filter defined in Eq. (9) for $\alpha \in\{0 ; 0.1 ; 0.2 ; 0.3 ; 0.4 ; 0.5\}$. and specific $\beta$ to obtain the same overshoot $A_{\mathrm{p}}=4.32 \%$.

TABle 1: VAlUES OF ADJUSTABlE PARAMETER $\beta$ TO MEET SPECIFIED REQUIREMENTS IN OVESRHOOT

\begin{tabular}{c|c}
\hline$\alpha$ & $\boldsymbol{\beta}$ \\
\hline 0 & $\sqrt{2} \approx 1.4142$ \\
\hline 0.1 & $0.8015 \sqrt{2} \approx 1.1335$ \\
\hline 0.2 & $0.7058 \sqrt{2} \approx 0.9982$ \\
\hline 0.3 & $0.6519 \sqrt{2} \approx 0.9219$ \\
\hline 0.4 & $0.6208 \sqrt{2} \approx 0.8779$ \\
\hline 0.5 & $0.6044 \sqrt{2} \approx 0.8547$ \\
\hline
\end{tabular}

The magnitude and phase response for FO band-pass filter with a damping factor $\beta_{\mathrm{d}}=\beta / s^{\alpha}, \beta>0$ in Eq. (7) are given with analytic formulae (10) and (11)

$$
\begin{gathered}
\left|F_{\mathrm{bp}}(\mathrm{j} \omega)\right|=\frac{\beta \omega^{1-\alpha}}{\sqrt{\left(1-\omega^{2}\right)^{2}+2 \beta \omega^{1-\alpha}\left(1-\omega^{2}\right) \sin \left(\frac{\alpha \pi}{2}\right)+\beta^{2} \omega^{2(1-\alpha)}}} \\
\angle F_{\mathrm{bp}}(\mathrm{j} \omega)=\frac{(1-\alpha) \pi}{2}-\operatorname{arctg} \frac{\beta \omega^{1-\alpha} \sin (\alpha \pi / 2)}{1-\omega^{2}+\beta \omega^{1-\alpha} \cos (\alpha \pi / 2)}
\end{gathered}
$$

while for notch filter described with Eq. (8), one obtains

$$
\begin{aligned}
\left|F_{\mathrm{n}}(\mathrm{j} \omega)\right|= & \frac{1-\omega^{2}}{\sqrt{\left(1-\omega^{2}\right)^{2}+2 \beta \omega^{1-\alpha}\left(1-\omega^{2}\right) \sin \left(\frac{\alpha \pi}{2}\right)+\beta^{2} \omega^{2(1-\alpha)}}} \\
& \angle F_{\mathrm{n}}(\mathrm{j} \omega)=-\operatorname{arctg} \frac{\beta \omega^{1-\alpha} \sin (\alpha \pi / 2)}{1-\omega^{2}+\beta \omega^{1-\alpha} \cos (\alpha \pi / 2)}
\end{aligned}
$$

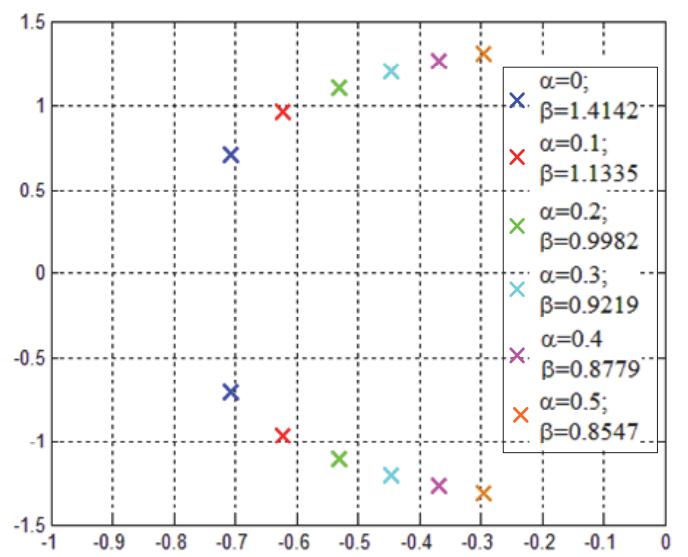

Fig. 2. Roots of characteristic equation of fractional-band pass filter $F_{\mathrm{bp}}(s)$ for $\alpha \in\{0 ; 0.1 ; 0.2 ; 0.3 ; 0.4 ; 0.5\}$. to obtain the same overshoot $A_{\mathrm{p}}=4.32 \%$ of $F_{\mathrm{lp}}(s)$ in Fig. 1 .

Values of the magnitude and phase for band-pass and notch filters at important frequencies are given in Table 2.

TABLE 2: MAGNITUDE AND PHASE VALUES AT IMPORTANT FREQUENCIES OF THE PROPOSED BAND-PASS AND NOTCH FILTERS

\begin{tabular}{c|c|c|c|c}
\hline$\omega$ & $\left|F_{\mathrm{bp}}(\mathrm{j} \omega)\right|$ & $\angle F_{\mathrm{bp}}(\mathrm{j} \omega)$ & $\left|F_{\mathrm{n}}(\mathrm{j} \omega)\right|$ & $\angle F_{\mathrm{n}}(\mathrm{j} \omega)$ \\
\hline$\omega \rightarrow 0$ & 0 & $\frac{(1-\alpha) \pi}{2}$ & 1 & 0 \\
\hline$\omega=\omega_{c}$ & 1 & 0 & 0 & $\begin{array}{c}(\alpha-1) \frac{\pi}{2} \text { for } \omega \rightarrow \omega_{c} \\
(\alpha+1) \frac{\pi}{2} \text { for } \omega \rightarrow \omega_{c+}\end{array}$ \\
\hline$\omega \rightarrow \infty$ & 0 & $-\frac{(\alpha+1) \pi}{2}$ & 1 & 0 \\
\hline
\end{tabular}

The magnitude and phase frequency responses of FO band-pass filter in Eq. (7) with a damping factor $\beta_{\mathrm{d}}=\beta / s^{\alpha}$ are shown in Fig. 3.

The bandwidth of band-pass filter in Eq. (7) shown in Fig. 3 for $\alpha=0$ is defined with a lower cut-off frequency $\omega_{\mathrm{cl}} \approx 0.52 s^{-1}$ and upper frequency $\omega_{\mathrm{c} 2} \approx 1.93 s^{-1}$. The magnitude and phase frequency responses of FO notch filter in Eq. (8) with a damping factor $\beta_{\mathrm{d}}=\beta / s^{\alpha}$ are shown in Fig. 4.

As it can be seen from Figs. 3 and 4, additional flexibility is supported by the use of presented band-pass and notch filter with a FO damping factor. By choosing an FO parameter it is enabled to adjust band-pass/band-reject and to decrease a large negative phase for notch filter which is important in some applications such as in system identification [36]. Indeed, there are increasing numbers of designs of FO filters with a possibility of adjusting and shaping a desired frequency response, e.g. in [44] is reported an electronic way of control of FO order and pole 
frequency of low-pass filter through adjustment of the current gain of current amplifiers.

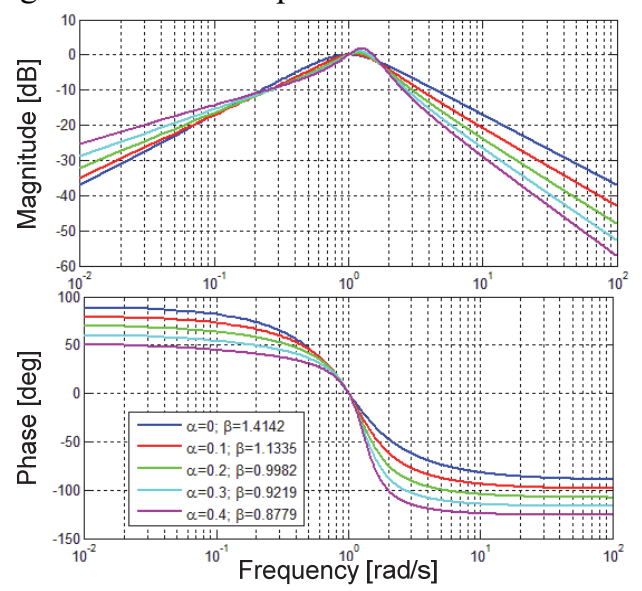

Fig. 3. The magnitude and phase frequency characteristics of fractional-band pass filter $F_{\mathrm{bp}}(s)$ for $\alpha \in\{0 ; 0.1 ; 0.2 ; 0.3 ; 0.4\}$. and specific $\beta$ to obtain the same overshoot $A_{\mathrm{p}}=4.32 \%$ of $F_{\mathrm{lp}}(s)$ in Fig. 1 .

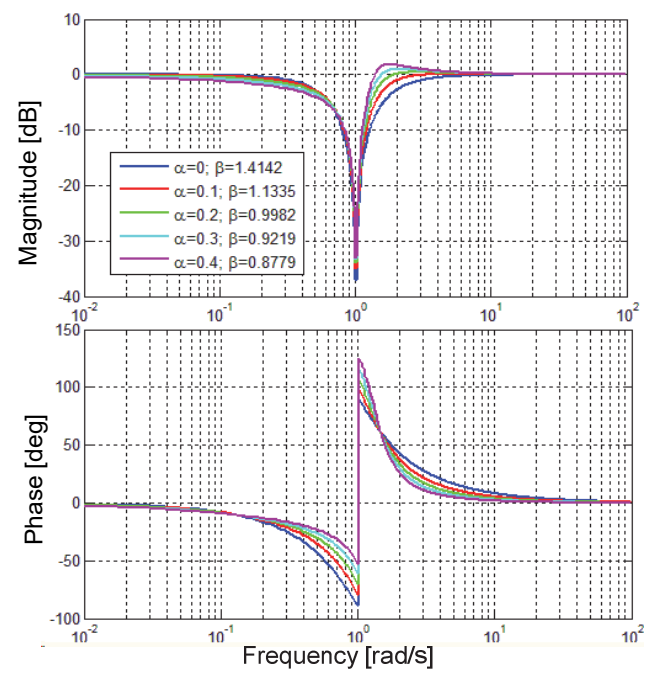

Fig. 4. The magnitude and phase frequency characteristics of FO notch filter $F_{\mathrm{n}}(s)$ for $\alpha \in\{0 ; 0.1 ; 0.2 ; 0.3 ; 0.4\}$. and specific $\beta$ to obtain the same overshoot $A_{\mathrm{p}}=4.32 \%$ of

$$
F_{\text {lp }}(s) \text { in Fig. } 1 .
$$

\section{ANALOG/DIGITAL REALIZATION OF FRACTIONAL- ORDER FILTERS}

The main building blocks of FO filters are fractional integrators and differentiators $s^{\alpha}$. FO differentiator is obtained for $0<\alpha<1$ while for $-1<\alpha<0$ it is reduced to FO integrator. Analog low-pass, high-pass, band-pass, notch and all-pass filters may be realized via various topologies of ladder networks consisting of resistors or/and capacitors or/and inductors. There are two general approaches in the design of an analog FO filter: the first is to approximate the FO filter transfer function with an integer-order equivalent and the second is using a FO element. The fabrication techniques of FO elements are nowadays well developed, but they are still an emerging area of research due to upcoming FO nanomaterials, which is elaborated in [35].
However, digital filters are principally characterized with more versatility, reliability, flexibility than analog filters in signal processing, as well as with programmability, i.e. without a need to redesign the hardware, etc. [41]. Digital realization of FO systems is supported with an adequate discretization method. The most popular methods are PSE (Power Series Expansion) and CFE (Continued Fraction Expansion) approximations of the fractional operators. A number of discretization schemes for purpose of digital implementation of FO systems is available in literature such as: bilinear transformation (Tustin or trapezoidal rule) which is widely used for discretization of filters, then forward Euler, backward Euler and other variations of $T$ integrator $[45,46]$. Direct and indirect discretization algorithms have been discussed in [47], novel transformation polynomials for discretization of analog systems are reported in [48], while an efficient method for discretization based on least-squares fitting in time domain is presented in [49].

In this paper, four discretization techniques of bandpass filter $F_{\mathrm{bp}}(s)$ denoted with: ORA, CFE, IFC and ARX are analysed. ORA and CFE make rational approximation of differ-integrator $s^{\alpha}$, IFC approximates directly a continuous filter transfer function. These three techniques are followed with one of discretization rules, while the fourth ARX based method directly discretizes the continuous-time system.

\section{A. Oustaloup recursive algorithm (ORA)}

ORA algorithm, elaborated in [50], for the approximation of FO differ-integrator $s^{\alpha}$ gives the following expression of $3^{\text {rd }}$ order for $\alpha=-0.2$

$$
\frac{1}{s^{0.2}} \approx \frac{0.2512 s^{3}+40.21 s^{2}+63.73 s+1}{s^{3}+63.73 s^{2}+40.21 s+0.2512}
$$

\section{B. Continued fractional expansion (CFE)}

CFE algorithm of $3^{\text {rd }}$ order for $s^{\alpha}$ around frequency $\omega=1 \mathrm{~s}^{-1}$ according to $[35, \mathrm{p} .4]$ is given with

$$
s^{\alpha} \approx \frac{\alpha_{0} s^{3}+\alpha_{1} s^{2}+\alpha_{2} s+\alpha_{3}}{\alpha_{3} s^{3}+\alpha_{2} s^{2}+\alpha_{1} s+\alpha_{0}}, \begin{gathered}
\alpha_{0}=\alpha^{3}+6 \alpha^{2}+11 \alpha+6 \\
\alpha_{1}=-3 \alpha^{3}-6 \alpha^{2}+27 \alpha+54 \\
\alpha_{2}=3 \alpha^{3}-6 \alpha^{2}-27 \alpha+54 \\
\alpha_{3}=-\alpha^{3}+6 \alpha^{2}-11 \alpha+6
\end{gathered}
$$

while for $\alpha=0.2$ one obtains

$$
s^{0.2} \approx \frac{8.448 s^{3}+59.136 s^{2}+48.384 s+4.032}{4.032 s^{3}+48.384 s^{2}+59.136 s+8.448}
$$

\section{Interpolation of frequency characteristic (IFC)}

IFC algorithm is directly applied to a filter transfer function $F_{\mathrm{bp}}(s)$ and approximates it through interpolation of frequency characteristic on the basis of overlapping the frequency characteristics in selected discrete frequency points [51]. For $\omega=[0.01 ; 0.1 ; 1 ; 10 ; 50]$ the $5^{\text {th }}$ order rational approximation of $F_{\mathrm{bp}}(s)$ is

$F_{\mathrm{bp}}^{\mathrm{IFC}}(s)=\frac{-6.74 \cdot 10^{-4} s^{5}+0.1986 s^{4}+4.1898 s^{3}+1.7527 s^{2}+0.00695 s-6.53 \cdot 10^{-5}}{s\left(0.4915 s^{4}+5.7387 s^{3}+5.6751 s^{2}+7.2929 s+1\right)}$ 
All of these methods of rational approximation (ORA, CFE, IFC) may be discretized in different ways, as previously discussed, but in this paper the Tustin rule $s=\frac{2(z-1)}{T_{S}(z+1)}$ is used, where $T_{\mathrm{s}}$ is a sampling time. Hence, by using the Tustin rule and taking $T_{\mathrm{s}}=0.06 \mathrm{~s}$ in (15), (17) and (18), one obtains the $5^{\text {th }}$ order discrete equivalents $F_{\mathrm{bp}}^{\mathrm{ORA}}(z), F_{\mathrm{bp}}^{\mathrm{CFE}}(z), F_{\mathrm{bp}}^{\mathrm{IFC}}(z)$, respectively.

\section{AutoRegressive with eXogenous input (ARX) based method}

In addition to the above, ARX-based direct discretization method for arbitrary non-rational systems, recently proposed in [52], is successfully applicable to FO filters. This method uses an one-period bipolar test signal shown in Fig. 5 at the input of filter and applies leastsquare routine to solve parameter estimation problem. By applying ARX based approximation algorithm, for a selected interval of length $T_{\mathrm{m}}=60 \mathrm{~s}$, time period $\Delta=20 \mathrm{~s}$ and $N=1000$ calculation points one obtains directly the transfer function of discrete equivalent of band-pass filter $F_{\text {bp }}(s)$

$F_{\text {bp } 5 / 5}^{\text {ARX }}(z)=\frac{0.01582 z^{5}-0.03165 z^{4}-0.00104 z^{3}+0.03961 z^{2}-0.02845 z+0.00572}{z^{5}-4.3148 z^{4}+7.3728 z^{3}-6.2213 z^{2}+2.5838 z-0.42052}$

with a sample time $T_{s}=T_{\mathrm{m}} / N=0.06 \mathrm{~s}$.

The comparison of presented discretization techniques is performed through the magnitude and the frequency characteristics of FO $G_{\mathrm{bp}}(s)$ and its discrete equivalent $G_{\mathrm{bp}}(z)$ as it is shown in Fig. 6. Vertical thick dark line in Fig. 6 and Fig. 7 denotes the Nyquist frequency.

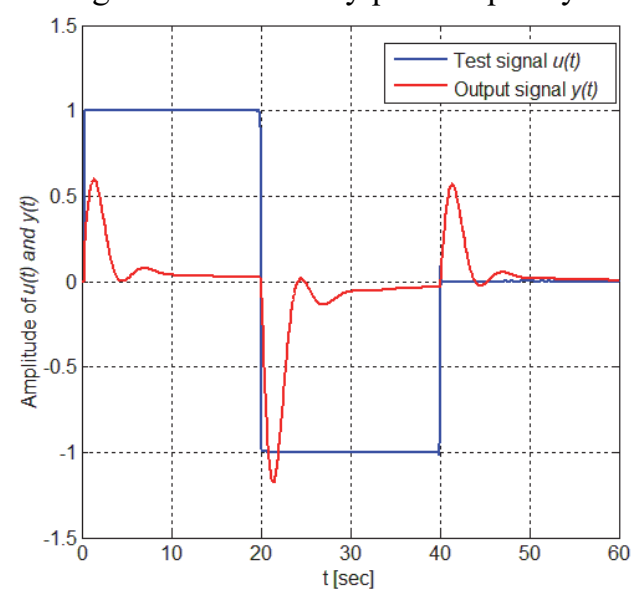

Fig. 5. Input $u(t)$ and output $y(t)$ for $T_{\mathrm{m}}=60 \mathrm{~s}$ and $\Delta=20 \mathrm{~s}$ used as data for ARX-based discretization of band-pass filter transfer function $F_{\mathrm{bp}}(s)$ for $\alpha=0.2$.

The obtained results indicate that all considered discretization methods retain frequency characteristics adequately over a wide frequency range. However, all of these approximation techniques can be somehow improved, e.g.: ORA by selection of a wider frequency range, IFC with more appropriate initial frequency points, ARX with selection of parameters $T_{\mathrm{m}}$ and $\Delta$, as well as with selection of higher order approximation, etc. Without loss of generality, the presented filter design approach and analysis including discretization techniques may be effectively applied to high-order fractional filters.

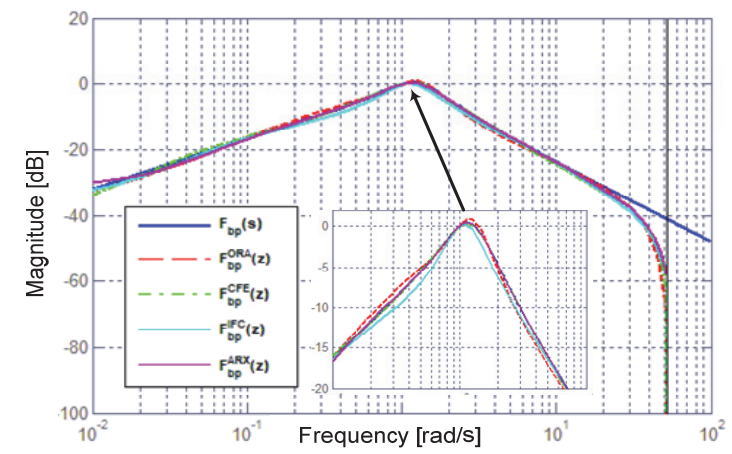

Fig. 6. Comparison of magnitude characteristics of $F_{\mathrm{bp}}(s)$ for $\alpha=0.2$ and discrete equivalents obtained with ORA, CFE, IFC (+Tustin) and ARX method.

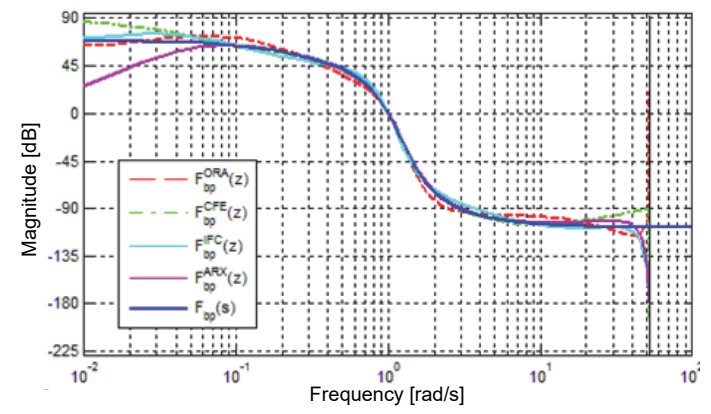

Fig. 6. Comparison of phase characteristics of $F_{\mathrm{bp}}(s)$ for $\alpha=0.2$ and discrete equivalents obtained with ORA,

CFE, IFC (+Tustin) and ARX method.

\section{CONCLUSION}

The second order band-pass and notch filters with a dynamic damping factor of fractional-order are analyzed in this paper. Conducted analysis shows that a fractionalorder parameter enables more precise and flexible shaping of the frequency responses of both filters which is of great importance in a large number of applications. At the end, several methods of discretization techniques are compared to demonstrate how these fractional-order filters may be effectively implemented in a digital form.

\section{REFERENCES}

[1] J.Tenreiro Machado, V. Kiryakova, F. Mainardi, "Recent history of fractional calculus", Communications in Nonlinear Science and Numerical Simulation, vol. 16, issue 3, pp. 1440-1153, 2011.

[2] In: Lazarević MP (editor), Advanced topics on applications of fractional calculus on control problems, system stability and modeling, WSEAS, p.202, ISBN:978-960-474-348-3, ID9028, 2014.

[3] K.B. Oldham, J. Spanier, Fractional calculus: theory and applications, differentiation and integration to arbitrary order, Academic Press, NewYork, 1974.

[4] A.A. Kilbas, H.M. Srivastava, J.J. Trujillo, Theory and Applications of Fractional Differential Equations, Elsevier, Amsterdam, 2006.

[5] I. Podlubny, Fractional Differential Equations, Academic Press, San Diego, 1999.

[6] R.L. Magin, Fractional Calculus in Bioengineering, Begell House Publishers, 684 pages, 2006.

[7] T. J. Freeborn, "A Survey of Fractional-Order Circuits Models for Biology and Biomedicine", IEEE J. Emerging and Selected Topics in Circuits and Systems, vol. 3, no. 3, pp, 416-424, Sept. 2013.

[8] A.G. Radwan. K.N. Salama, "Passive and Active Elements Using Fractional $\mathrm{L}_{\beta} \mathrm{C}_{\alpha}$ Circuit", IEEE Trans on Circuits and Systems-I, vol. 58, no. 10, pp. 2388-2397, Oct. 2011.

[9] A.G. Radwan, K.N. Salama, "Fractional-order RC and RL circuits. Circuits Syst. Signal Process, vol. 31, pp. 1901-1915, 2012. 
[10] G.W. Bohannan, S.K. Hurst, and L. Spangler, Electrical Component with Fractional-Order Impedance, U.S. Patent Application, No. $11 / 372,232,2006$

[11] M.Č. Bošković, T.B. Šekara, B. Lutovac, M. Daković, P.D. Mandić, M.P. Lazarević, "Analysis of Electrical Circuits including Fractional Order Elements", $\sigma^{\text {th }}$ Mediterranean Conference on Embedded Computing (MECO), pp. 1-6, Bar, Montenegro, 2017.

[12] C. Coopmans, I. Petras, and Y.Q. Chen, "Analogue fractional-order generalized memristive devices," in ASME 2009 Int. Design Eng. Tech. Conf. Comput. Inf. Eng. Conf. (IDETC/CIE), San Diego, USA, 2009.

[13] M.P. Lazarević, P.D. Mandić, B. Cvetković, T.B. Šekara, B. Lutovac, "Some Electromechanical Systems and Analogies of Mem-systems Integer and Fractional Order", $5^{\text {th }}$ Mediterranean Conference on Embedded Computing, pp. 230-233, MECO 2016, Bar, Montenegro

[14] C. Wu, G. Si, Y. Zhang, N. Yang, "The fractional-order state-space averaging modelling of the Buck-Boost DC/DC converter in discontinuous conduction mode and the performance analysis", Nonlinear Dynamics, vol.79, issue 1, pp. 689-703, Jan. 2015.

[15] A.G. Radwan, A.A. Emira, A.M. AbdelAty, A.T. Azar, "Modeling and analysis of fractional order DC-DC converter", ISA Transactions, 2017. DOI:10.1016/j.isatra.2017.06.024

[16] X. Chen, Y.Chen, B. Zhang, D. Qiu, "A Modeling and Analysis Method for Fractional-Order DC-DC Converters", IEEE Trans on Power Electronics, vol. 32, issue 9, pp. 7034-7044, Sept 2017.

[17] D. Chen, Y. Chen Y, D. Xue, "Fractional-order total variation image denoising based on proximity algorithm", Applied Mathematics and Computation, vol. 257, pp. 537-545, April 2015.

[18] L.A. Said, S.M. Ismail, A.G. Radwan, A.H. Madian, M.F. Abu ElYazeed, A.M. Soliman, "On The Optimization of Fractional Order Low-Pass Filters", Circuits Systems and Signal Processing, vol. 35, Issue 6, pp. 2017-2039, June 2016.

[19] J.A. Tenreiro Machado, I.S. Jesus, A. Galhano, J.B. Cunha, "Fractional order electromagnetics", Signal Processing, vol. 86, pp. 2637-2644, 2006.

[20] A. Shamim, A.G. Radwan, K.N. Salama, "Fractional smith chart theory and application", IEEE Microwave and Wireless Components Letters, vol. 21, issue 3, pp. 117-119, March 2011.

[21] R.F. Camargo, E.C. de Oliveira, E., J. Vaz Jr., "On the generalized Mittag-Leffler function and its application in a fractional telegraph equation", Math. Phys. Anal. Geom, vol. 15, pp. 1-16 2012

[22] S.M. Cvetićanin, D. Zorica, M.R. Rapaić, "Generalized timefractional telegrapher's equation in transmission line modeling", Nonlinear Dynamics, vol. 88, pp. 1453-1472, April 2017.

[23] A. Pommier, J. Sabatier, P. Lanusse, A. Oustaloup, "CRONE Control of a Nonlinear Hydraulic Actuator", Control Engineering Practice, vol. 10, issue 4, pp. 391-402, 2002.

[24] J. Sabatier, A. Oustaloup, A.G. Iturricha, F. Levron, "CRONE Control of Continuous Linear Time Periodic System: Application to a Testing Bench", ISA Transactions, vol. 42, Issue 3, pp. 421-436, 2003.

[25] I. Petráš, "Tuning and implementation methods for fractional-order controllers", Fractional Calculus and Applied Analysis, vol. 15, pp. issue 2, pp. 282-303, June 2012.

[26] B.B. Jakovljević, M. R. Rapaić, Z.D. Jeličić, T.B. Šekara, "Optimization of distributed order fractional PID controller under constraints on robustness and sensitivity to measurement noise", International Conference on Fractional Differentiation and It. Applications (ICFDA), pp. 1-6, Catania, June 2014

[27] P.D. Mandić, T.B. Šekara, M.P. Lazarević, M. Bošković, "Dominant pole placement with fractional order PID controllers: Ddecomposition approach", ISA Transactions, vol. 67, pp. 76-86, 2017.

[28] K.A. Lazopoulos, A.K. Lazopoulos, "Fractional derivatives and strain gradient elasticity", Acta Mechanica, vol. 227, issue 3, pp. 823-835, March 2016.

[29] S.S. Sheoran, K.K. Kalkal, S. Deswal, "Fractional order thermoviscoelastic problem with temperature dependent modulus of elasticity", Mechanics of Advanced Materials and Stuctures, vol. 23, issue 4, pp. 407-414, 2016.

[30] T.M. Atanackovic, S. Pilipovic, D. Zorica, "A diffusion wave equation with two fractional derivatives of different order", Journal of Physics A: Mathematical and Theoretical, vol. 40, no. 20, pp. 5319-5333, 2007.
[31] M.R. Rapaić, Z.D. Jeličić, "Optimal control of a class of fractional heat diffusion systems", Nonlinear Dynamics, vol. 62, issue 1-2, pp. 39-51, Oct. 2010.

[32] G.M. Mophou, "Optimal control of fractional diffusion equation", Computers \& Mathematics with Applications, vol. 61, issue 1, pp. 68-78, Jan. 2011.

[33] D. Sierociuk, T. Skovranek, M. Macias, I. Podlubny, I. Petras, A. Dzielinski, P. Ziubinski, "Diffusion process modeling by using fractional-order models", Applied Mathematics and Computation, vol. 257, pp. 2-11, April 2015.

[34] K. Biswas, G. Bohannan, R. Caponetto, A. Mandes Lopes, J.A. Tenreiro Machado, Fractional-Order Devices, Springer Int Publishing, 2017.

[35] G. Tsirimokou, C. Psychalinos, A. Elwakil, Design of CMOS Analog Integrated Fractional-Order Circuits, Applications in Medicine and Biology, Springer Int Publishing, 2017.

[36] T.B. Šekara, M.R. Mataušek, "Relay-based critical point estimation of a process with the PID controller in the loop", Automatica, vol. 47, issue 5, pp. 1084-1088, May 2011.

[37] J. Baranowski, P. Piątek, "Fractional Band-Pass Filters: Design, Implementation and Application to EEG Signal Processing", Journal of Circuits, Systems, and Computers, vol. 26, issue 11, pp. 1-21, No. 11, 2017.

[38] A.S. Ali, A.G. Radwan, A.M. Soliman, "Fractional Order Butterworth Filter: Active and Passive Realizations", IEEE journal on Emerging and Selected Topics in Circuits and Systems, vol. 3, issue 3, pp. 346-354, Sept. 2013.

[39] A. Acharya, S. Das, I. Pan, S. Das, "Extending the concept of analog Butterworth filter for fractional order systems", Signal Processing, vol. 94, pp. 409-420, 2014.

[40] C-C Tseng, S-L Lee, "Closed-form designs of digital fractional order Butterworth filters using discrete transforms", Signal Processing, vol. 137, pp. 80-97, 2017.

[41] L.D. Paarmann, Design and Analysis of Analog Filters: A Signal Processing Perspective, Springer, Berlin, 2001.

[42] A.M. AbdelAty, A. Soltan, W.A. Ahmed, A.G. Radwan, "On the Analysis and Design of Fractional-Order Chebyshev Complex Filter", Circuits, Systems and Signal Processing, vol 37, issue 3, pp 915-938, March 2018

[43] S. Butterworth, "On the theory of filter amplifiers", Wireless Engineer, vol. 7, 536-541, 1930.

[44] J. Dvorak, L. Langhammer, J. Jerabek, J. Koton, R. Sotner, J. Polak, „Synthesis and Analysis of Electronically Adjustable Fractional Order Low-Pass filter", Journal of Circuits, Systems, and Computers, vol. 27, issue 2, Feb. 2018.

[45] R. Boxer, S. Thaler, "A Simplified Method of Solving Linear and Nonlinear Systems", Proceeding of IRE, vol. 44, no. 1, pp. 89-101, Jan. 1956.

[46] J.M. Smith, Mathematical Modeling and Digital Simulation for Engineers and Scientists, Second Ed., Wiley, New York, 1987.

[47] M.R. Rapaić, T.B. Šekara, "Novel direct optimal and indirect method for discretization of linear fractional systems", Electrical Engineering, vol. 93, issue 2, pp. 91-102, June 2011.

[48] T.B. Šekara, "New Transformation Polynomials for Discretization of Analogue Systems", Electrical Engineering, vol. 89, issue 2, pp. 137-147, Dec. 2006.

[49] R.S. Barbosa, J.A. Tenreiro Machado, M.F. Silva, "Time domain design of fractional differintegrators using least-squares", Signal Processing, vol. 86, issue 10, pp. 2567-2581, Oct. 2006.

[50] A.Oustaloup, F. Levron, B. Mathieu, F.M. Nanot, "Frequency-band complex noninteger differentiator: characterization and synthesis", IEEE Transactions on Circuits and Systems I: Fundamental Theory and Applications, vol. 47, issue 1, pp. 25-39, Jan. 2000.

[51] M.R. Rapaić, T.B. Šekara, M.P. Lazarević, "On discrete finite dimensional approximation of linear, infinite dimensional systems", in Fractional Calculus Theory, Mathematics Research Developments, pp. 257-274, 2014. ISBN 978-1-63463-002-3

[52] M.Č. Bošković, T.B. Šekara, M. Rapaić, M. Lazarević, P. Mandić, "A Novel ARX-based discretization method for linear non-rational systems", International Conference on Fractional Differentiation and its Applications (ICFDA 2016), vol. 1, pp. 343-352, Novi Sad, Serbia, July 2016, ISBN: 978-86-7892-830-7

[53] M. Bošković, T.B. Šekara,, M.R. Rapaić, B. Lutovac, M. Daković, V. Govedarica, "Novel band-pass and notch filter with dynamic damping of fractional order", 25th Telecommunication Forum (TELFOR), Belgrade, Serbia, 21-22 Nov. 2017. 